\title{
EXISTÊNCIA E CONCRETUDE: O MARXISMO HEIDEGGERIANO DE MARCUSE
}

\section{Cicero Lourenço da Silva*}

Resumo: Este texto pretende sublinhar a influência da obra de Heidegger no pensamento de Herbert Marcuse, registrada nos primeiros escritos deste filósofo, na década de 30 (século XX). Veremos como Marcuse incorpora certos conceitos heideggerianos no marxismo que desenvolveu naquele período, até o momento que sua obra, "superando" esse heideggerianismo passa a ser matizada por outros pressupostos, a saber, Hegel, Marx e o projeto frankfurtiano.

Palavras-chave: Marcuse, práxis, grande recusa, Dasein

\section{Herbert Marcuse e o "marxismo heideggeriano"}

A posição marxista de Herbert Marcuse - como foi observado por Kellner ${ }^{2}$ - remonta à sua leitura de duas obras que tiveram influência decisiva em sua visão posterior. A primeira delas é o clássico História da Consciência de Classe de Georgy Lukaks e a outra é Marxismo e Filosofia de Karl Korsch, ambas publicadas no ano de 1923, quando Marcuse tinha apenas 25 anos. Desse seu envolvimento com o marxismo origina-se uma vasta obra que vai se ampliando conceitualmente nas décadas seguintes, sempre dialogando com os acontecimentos políticos do momento. Algumas delas afirmam-se como clássicos do pensamento filosófico, como sua Razão e Revolução, na qual o

\footnotetext{
*Cicero Lourenço da Silva é mestrando em Filosofia pela UNIFESP, sob orientação da profa Dra Jacira de Freitas. Existência e Concretude é um excerto inédito de sua dissertação "Herbert Marcuse; da Grande Recusa à Emancipação", a ser defendida em novembro de 2014. Contato: cicerophiloenglish@gmail.com ${ }^{2}$ KELLNER, Douglas, Herbert Marcuse and the Crisis of Marxism, 1984, University of California Press. p. 69. O autor afirma: "Marcuse disse-me que acreditava que Korsch e Lukacs representavam a corrente 'mais autêntica' do marxismo. No original: "Marcuse told me that He believed that Korsch and Lukacs represented the 'most authentic' current of Marxism." É importante destacar que a referência diz respeito ao posicionamento de Marcuse no início da década de 30.
} 
filósofo esmiúça o pensamento de Hegel. ${ }^{3}$ Eros e Civilização é também celebrada como obra de peso, não necessariamente por fornecer uma interpretação "correta" do pensamento de Freud, mas pela originalidade de seu empreendimento, por alguns reputado como uma das mais ousadas incursões na metapsicologia freudiana, como afirma Kelnner ${ }^{4}$. Já a Ideologia da Sociedade Industrial, foi obra de impacto pela sua relevância política ${ }^{5}$, que ecoou inclusive nas manifestações de 68 , e cuja argumentação faz de seu autor, malgré lui, uma espécie de avatar da revolução.

Não obstante, o pensamento maduro do filósofo exposto nos escritos acima compõe-se de um alicerce que vinha sendo edificado desde seu encontro com a filosofia de Heidegger, da qual extrai, a princípio um marxismo heideggeriano. Esclarecemos que o termo é posterior, gerado pelos comentadores de Marcuse. Aliás, esse é um ponto sobre o qual Jurgen Habermas já chamara a atenção na década de 60. A passagem encontra-se no final da introdução da primeira obra de Marcuse, A Ontologia de Hegel, na qual, o autor afirma: "Qualquer contribuição que este trabalho possa dar ao desenvolvimento e esclarecimento de problemas há uma divida para com o trabalho filosófico de Heidegger. " 6

O próprio Habermas, ao citar a passagem acima esclarece que não tivera oportunidade de questionar Marcuse acerca de tal asserção - observação que fez em 1968, um ano em que as ideias de Marcuse estavam em alta, e, equivocadamente ou não, davam a tônica aos muitos protestos liderados pelo movimento estudantil.

Com a publicação de uma coletânea de textos de Marcuse contendo exclusivamente seu pensamento relacionado com a filosofia de Heidegger publicado no ano do centenário de Herbert Marcuse (1998), essa ideia adquire maior

\footnotetext{
${ }^{3}$ A obra Marcuse no Brasil, de Jorge Coelho Soares (edições Cefil, Londrina PR, 1999), traz entrevistas com intelectuais brasileiros cuja memória reconstrói a recepção da obra de Marcuse no Brasil na década de sessenta. O professor Nelson Coutinho, por exemplo, refere que utilizava (em 1999, ano da entrevista) Razão e Revolução como uma introdução "didática" a Hegel. Experiência idêntica á minha que primeiramente conheci Marcuse também num curso sobre Hegel com o professor Dr. Rodney Nascimento, na primeira turma de filosofia da Unifesp, iniciada em 2007.

${ }^{4}$ Cf. KELNNER, Douglas in "Schoolman on Marcuse" artigo disponível na página de Douglas Kellner, no site da www.ucla.com p. 16. Neste artigo, Kellner procura rebater o professor Morton Schoolman, que em sua obra The Imaginary Witness, na página 90, opõe Freud a Marcuse, afirmando que este teria distorcido aquele em sua interpretação constante em Eros e Civilização.

${ }^{5}$ KELLNER, Douglas, in MARCUSE, Herbert, The One Dimensional Man, in Introduction to the Second Edition. Ali nos remete aos capítulos de 7-10 de Herbert Marcuse and the Crisis of Marxism, onde aborda as influências, temas e impactos de One-dimensional man.

${ }^{6}$ Apud WOLIN, Richard, na longa epígrafe que abre sua introdução a Heideggerian Marxism. A fonte original citada por Wolin é Antworten auf Herbert Marcuse, ed.Jürgen Habermas (Frankfurt: Suhrkamp, 1968), 10-11.
} 
reconhecimento. ${ }^{7}$ A referida antologia trazida à luz naquele ano, expunha o pensamento "proto-heideggeriano" de Herbert Marcuse, desde sua adesão à filosofia do autor de Ser e Tempo, além de esclarecimentos acerca de seu ulterior afastamento daquela corrente filosófica. Há nessa ruptura razões de ordem puramente filosófica - que possuem maior relevância para esse trabalho e serão expostas no momento oportuno - como também outras de ordem pessoal, atinentes à posição política de Heidegger - sobre as quais não nos debruçaremos, sob o risco de relevar em demasia aspectos que não dão conta da genialidade filosófica do autor de Ser e tempo.

Essa obra é publicada em 1927. Sua filosofia causaria um grande impacto no pensamento de Marcuse, que, segundo relata Richard Wolin ${ }^{8}$ estava também envolvido com algumas das escolas filosóficas em ebulição em sua época. A academia trazia em seus seminários as grandes escolas comuns no período imediatamente anterior à guerra. Era o momento do positivismo, do neokantismo e do neo-hegelianismo. Marcuse era parte de uma geração inconformada com os horrores da primeira guerra, evento que exigia posicionamento filosófico e político de alcance superior àqueles possíveis dentro das escolas supracitadas. Wolin esclarece ainda que: "Para a geração mais jovem, contudo, os horrores da primeira Guerra representavam um ponto sem volta: as visões e perspectivas sobre o mundo que haviam predominado até então, antes de 1914, pareciam inteiramente vazias de legitimidade""

A obra de Heidegger e as questões que esta levantava atraíram Marcuse novamente para a universidade, onde, na companhia de outros destacados membros da intelligentzia alemã - Hannah Arendt, Han-Georg Gadamer, Karl Lowith, entre outros, percebeu naquele novo pensamento uma filosofia cuja relevância proporcionava as ferramentas teóricas adequadas a um enfrentamento das novas exigências do real. Acerca desse momento, registrou: "Para mim e meus amigos, a obra de Heidegger aparecia como um novo começo: provamos do seu livro (Ser e Tempo e suas palestras, das quais obtínhamos as transcrições) como uma filosofia finalmente concreta: aqui ela falava da existência, de nossa existência, do medo, do cuidado, do tédio e assim por diante. Também vivenciamos uma emancipação acadêmica: A

\footnotetext{
${ }^{7}$ Sabíamos já na publicação de A Escola de Frankfurt de Wiggerhaus, acerca desta passagem. Não obstante, pelo menos na pesquisa acadêmica de língua inglesa, havia ainda uma lacuna documental que impedia incursões mais detalhadas àquele período da obra de Marcuse.

${ }^{8}$ WOLIN, Richard, In MARCUSE, Herbert - Heideggerian Marxism - Introduction: What is heideggerian Marxism? Edited by Richard Wolin and John Abromeit - University of Nebraska Press, 2005.

${ }^{9}$ Idem, p. xxi, Introduction. No original ingles: For the younger generation, however, the horrors of World War I represented a point of no return: the worldviews and perspectives that had predominated prior to 1914 seemed entirely delegitimated.
} 
interpretação de Heidegger da filosofia grega e do idealismo alemão, que nos ofereciam novos prismas sobre textos antiquados, fossilizados. "10

A passagem mostra a ânsia dos pensadores em responder aos desafios do momento. Para tanto, buscavam as bases numa filosofia cujos princípios se relacionassem diretamente com a vida, isto é, uma abordagem filosófica legitimamente concreta. É preciso que nos demoremos um pouco na análise dessa noção, dada a sua importância para o projeto filosófico-político marcuseano. Nesse contexto, concreto é um conhecimento de relevância imediata para a existência do homem enquanto ser projetado no mundo, isto é, um saber capaz de fornecer-lhe ferramentas críticas para enfrentar os pressupostos ideológicos da dominação. Já com conceitos heideggerianos em mãos, Marcuse assim se pronuncia nos seus escritos de juventude - publicados originalmente em alemão na década de 20 - acerca do que ele entende por uma filosofia autêntica: "A filosofia autêntica se recusa a permanecer no estágio do conhecimento; direcionando este conhecimento, ao contrário, rumo à verdade, ela luta pela apropriação concreta dessa verdade até que chegue ao Dasein humano. A preocupação com a existência humana e sua verdade torna uma filosofia uma "ciência prática" no sentido mais profundo, e conduz ainda a filosofia - e este é o ponto crucial para dentro do conflito da existência humana." 11

Como o texto revela, nesse período, suas convicções marxistas incipientes encontram-se com os seminários de Heidegger, cuja ênfase recaía em pontos concretamente relacionados com a vida, ou numa terminologia já heideggeriana, com a existência. Conforme explica Wolin ${ }^{12}$, na obra Ser e Tempo a "analítica existencial" traz duas categorias, a saber, "temporalidade e historicidade”, nas quais, evidentemente

\footnotetext{
${ }^{10}$ MARCUSE, Herbert. "Postcript: My disillusionment with Heidegger", in Heideggerian Marxism, $p$. 176. Edited by Richard Wolin and John Abromeit - University of Nebraska Press, 2005. No original inglês: To me and my friends, Heidegger's work appeared as a new beginning: we experienced his book [Being and Time] (and his lectures, whose transcripts we obtained) as, at long last, a concrete philosophy: here there was talk of existence [Existenz], of our existence, of fear and care and boredom, and so forth. We also experienced an 'academic' emancipation: Heidegger's interpretation of Greek philosophy and German idealism, which offered us new insights into antiquated, fossilized texts." (tradução minha)

${ }^{11}$ MARCUSE, Herbert - On Concrete Philosophy, in Heideggerian Marxism - Edited by Richard Wolin and John Abromeit - University of Nebraska Press, 2005. A citação original é: "Authentic philosophizing refuses to remain at the stage of knowledge; rather, in driving this knowledge on to truth it strives for the concrete appropriation of that truth through human Dasein. Care (Sorge) for human existence and its truth makes philosophy a "practical science" in the deepest sense, and it also leads philosophy - and this is the crucial point - into concrete distress (Bedrängnis) of human existence".
}

12 WOLIN, Richard, What is heideggerian Marxism? Introduction, in MARCUSE, Herbert Heideggerian Marxism - Edited by Richard Wolin and John Abromeit - University of Nebraska Press, 2005. P.xii. 
“o Dasein se vê imerso". Ao abordar a questão da autenticidade - central à sua filosofia

- Heidegger considera a capacidade que o homem tem de atualizar o passado à luz das possibilidades futuras. A posição oposta - ou inautêntica - é representada pela aceitação passiva e conformista do dado como expressão última do real, o que deixa o homem em situação semelhante ao ser das "coisas", num lastimável processo de reificação. Acresce notar, que tal filosofia, como esclarece Wolin ${ }^{13}$, ainda trazia o selo do rigor científico, já que engendrada sob o pensamento fenomenológico de Edmund Husserl (1859 - 1938). Tal condição emprestava-lhe solidez suficiente para confrontar o cientificismo reinante do período, uma vez que aquele, respeitável herdeiro do Positivismo da Escola de Viena, aparecia como a única ferramenta capaz de depor uma metafísica que alguns viam com suspeita. A filosofia de Heidegger, ainda segundo Wolin, afastava-se do viés ainda um tanto romântico das "filosofias de vida" 14 populares em seu tempo.

Notemos ainda que a atração que a filosofia de Heidegger tivera para Marcuse deveu-se também, em parte, à chamada crise do marxismo. Rosa Luxemburgo fora enfática em sua condenação do vanguardismo de Lenin, sobretudo ao considerar que tal ação mostrava-se bastante inadequada para outros países da Europa Central e Ocidental, onde o proletariado encontrava-se já maduro para a ação revolucionária. ${ }^{15}$

Dessa interação com o trabalho de Martin Heidegger e o confronto com os acontecimentos históricos de então, decorrem as primeiras reflexões críticas de Marcuse sobre o papel da técnica. E é também quando consolida o seu programa filosófico de uma filosofia concreta:

"Se ao nos voltarmos para o Ser e o Tempo de Heidegger nos demoramos nele mais do que poderia ser necessário nesse contexto ${ }^{16}$, é por que este livro representa uma virada na história da filosofia: o ponto no qual a filosofia burguesa se desfaz de dentro para fora e pavimenta o caminho para uma ciência "concreta". ${ }^{17}$

\footnotetext{
${ }^{13}$ Idem, p. xiii

${ }^{14}$ Richard Wolin, ao referir-se às "filosofias de vida populares ao tempo de Heidegger", e de quem este se afastava, menciona dois autores alemães: Oswald Spengler e Ludwig Klages.

${ }^{15}$ WOLIN, Richard, opus cit. p. xiv

${ }^{16} \mathrm{O}$ contexto a que se refere aqui é o problema da historicidade.

${ }^{17}$ MARCUSE, Herbert, Contributions to a Phenomenology of Historical Materialism, in Heideggerian Marxism. Originalmente escrito em 1927, retraduzido para o ingles em 1998 para a antologia citada. A citação acima tem tradução de nossa responsabilidade, do texto assim transcrito em inglês: If, in turning toward Heidegger's Being and Time, we linger somewhat longer than might be necessary in this context, it is because this book seems to represent a turning point in the history of philosophy: the point at which bourgeois philosophy unmakes itself from the inside and clears the way for a new and "concrete"
} 
Sua adoção de princípios heideggerianos servia assim à criação de uma filosofia marxista em seus pressupostos, coerente com as necessidades históricas do momento. O marxismo compreendido numa linha ortodoxa, mostrava-se teoricamente insuficiente para um enfrentamento que exigia uma práxis específica àquele momento. Kellner cita o papel dos acontecimentos históricos de então e o impacto que causaram nos círculos marxistas frankfurtianos:

"Em vista do triunfo do fascismo, da tirania stalinista e do fracasso concomitante do proletariado no Ocidente em emergir como o agente revolucionário, o Instituto começou a questionar características centrais da teoria marxiana do socialismo e da revolução" 18

O constatação desse cenário político torna discutível a noção de que o proletariado estava determinado ao desempenho de uma missão revolucionária histórica, segundo a qual, transitaria da dominação à revolta, e desta para a tomada subversiva do poder burguês. Sergio Paulo Rouanet, apoiado na Psicanálise, assim elucida esse momento histórico:

"A psicanálise é convocada para explicar a ação irracional da classe operária, isto é, a circunstância de que suas opções políticas contradiziam diretamente os seus interesses de classe. A realidade materialmente opressora impunha uma política revolucionária; a ideologia tentava neutralizar num sentido conservador, os impulsos contrários ao statu quo (sic); o fato a ser explicado consistia na vitória excessivamente fácil da ideologia sobre a realidade, explicação que o marxismo clássico não tinha condições de fornecer e que foi encontrada no freudismo." 19

Diante deste impasse histórico, Lenin promove uma leitura particular da revolução do proletariado, que ocorreria sob a égide de uma vanguarda revolucionária. ${ }^{20} \mathrm{O}$ amplo campesinato russo e a inexistência de um processo maduro de industrialização justificaria o adendo teórico, do qual, infelizmente resultaram efeitos pouco consoantes com o caráter emancipatório do marxismo clássico.

science.. Pareceu-nos importante salientar que já conhecíamos a passagem, citada por Rolf Wiggershaus, em seu monumental A Escola de Frankfurt (Difel, 2006, RJ. Ali, a referida passagem aparece traduzida do alemão, da seguinte forma: "A obra de Heidegger encarnava o ponto em que a filosofia burguesa é transcendida dentro de si própria em direção à nova filosofia, à filosofia concreta" (Schriften 1, 358 e $385)$.

${ }^{18}$ KELLNER, Douglas, in MARCUSE, Herbert, Towards a critical theory of society: Introduction (The collected papers of Herbert Marcuse, vol. II) p. 5. No original inglês: "In view of the triumph of fascism, Stalinist tyranny and the concomitant failure of the proletariat in the West to emerge as a revolutionary agent, the Institute began to question central features of the Marxian theory of socialism and revolution". ${ }^{19}$ ROUANET, Sérgio Paulo, Teoria Crítica e Psicanálise, Tempo Brasileiro, (Col. Biblioteca Tempo Universitário - 66) Rio de Janeiro, 2001.

20 Para uma retomada do argumento da vanguarda revolucionária, remetemos o leitor à obra Que Fazer? Questões importantes do movimento operário, LENIN, Wladmir Ilich Ulianov, Estudos Vermelhos, 2013. 


\section{Outros Elementos Heideggerianos e sua superação}

A presença de outras categorias heideggerianas é algo patente na obra de Marcuse na década de trinta. Nessa fase incipiente, quando o filósofo não formara ainda uma teoria social própria, grande parte de seus escritos abordavam questões relacionadas com a práxis e teoria revolucionária marxianas. Não obstante, como já referimos, teoria socialista passava por revisões que favorecia a ação de grupos com os quais Marcuse divergia filosoficamente.

Sua noção de práxis política radicalizava-se patentemente. Se as condições históricas concretas assim o exigissem, ou seja, se a vida social se tornasse intolerável do ponto de vista psicossocial e humanitário, a ação racional traduzir-se-ia num ato radical, conceito congênere ao de Grande recusa que se consolida em Eros $e$ Civilização e permeia a obra de maturidade do filósofo. O que demanda um ato radical, uma ruptura extrema para com o status quo, é o fato de este último ter-se tornado uma agressão às possibilidades autênticas de uma existência feliz. O Ato radical é um ato de rejeição de uma certa situação histórica vivenciada como intolerável. ${ }^{21}$

O ato radical é a defesa da autenticidade, portanto. A decisão pelo ato radical parte do indivíduo socialmente vitimado, o que torna o ato, nos termos da filosofia de Heidegger, claramente um ato existencial. Neste ponto, inicia-se uma crítica sutil à filosofia heideggeriana constante em Ser e Tempo, uma vez que lá, a ênfase é colocada na subjetividade. $\mathrm{O}$ ato radical ainda que se inicie como um ato motivado pelo indivíduo, ${ }^{22}$ não tem como efetivar-se numa revolução se for privado de certos elementos. Nos primeiros escritos, Marcuse defende que indivíduos possam realizar atos radicais, sem jamais postular uma revolução sem um proletário revolucionário com consciência de classe" ${ }^{\text {23 }}$. Por esse período o pensamento de Heidegger vai se eclipsando na obra de Marcuse, e encaminha-se para a elaboração de um marxismo próprio,

\footnotetext{
${ }^{21}$ Cf. KELLNER, Douglas, Herbert Marcuse and the Crisis of Marxism, 1984, University of California Press. p. 41

${ }^{22}$ Douglas Kellner explica ainda na p. 48, que para Marcuse, o indivíduo autêntico de Heidegger não é realmente radical, já que ocupa-se apenas com sua própria autenticidade. Uma vez realizada esta, permanece como conquista individual, sem reflexos emancipatórios na sociedade alienada. Ou, nas palavras textuais de Kellner: "Um ato radical, na visão de Marcuse, deve transformar o eu e as condições da existência, enquanto que para Heidegger, o indivíduo autêntico ocupa-se basicamente com sua autenticidade pessoal e não com uma mudança da sociedade". (No original inglês: "Radical act, on Marcuse's account, must transform the self and the conditions of existence, whereas for Heidegger, the authentic individual is basically concerned with his or her own personal authenticity and not with changing society. Ver KELLNER, Douglas - Herbert Marcuse and the crisis of Marxism, p. 48.

${ }^{23}$ Cf.KELLNER, Douglas - Herbert Marcuse and the crisis of Marxism, p. 42.
} 
partindo de outros pressupostos: Hegel e Marx, já com leituras distintamente frankfurtianas.

\section{Referências}

KELNNER, Douglas in "Schoolman on Marcuse" artigo disponível na página de Douglas Kellner, no site da www.ucla.com p. 16 (1982)

KELLNER, Douglas, Herbert Marcuse and the Crisis of Marxism, 1984, University of California Press.

KELLNER, Douglas, in MARCUSE, Herbert, Towards a critical theory of society: Introduction (The collected papers of Herbert Marcuse, vol. II)

LENIN, Wladmir Ilich Ulianov, Que Fazer? Questões importantes do movimento operário , Estudos Vermelhos, 2013

MARCUSE, Herbert - Heideggerian Marxism, Edited by Richard Wolin and John Abromeit - University of Nebraska Press, 2005

MARCUSE, Herbert - On Concrete Philosophy, in Heideggerian Marxism - Edited by Richard Wolin and John Abromeit - University of Nebraska Press, 2005

ROUANET, Sérgio Paulo, Teoria Crítica e Psicanálise, Tempo Brasileiro, (Col. Biblioteca Tempo Universitário - 66) Rio de Janeiro, 2001.

SOARES, Jorge Coelho, Marcuse no Brasil, edições Cefil, Londrina PR, 1999 